\title{
COVID-19 Recession: The Global Economy in Crises
}

\author{
Prof. Dr. Mehmet Balc1lar (Eastern Mediterranean University, TR of Northern Cyprus)
}

\begin{abstract}
In January 2020, the International Monetary Fund (IMF) predicted that the world economy would grow by $3.3 \%$ in 2020. However, in its latest forecasts, in April, it predicts a contraction of 3.0\%, without growth prospects and with numerous risks. The World bank even forecasts a 3.6\% contraction in 2020 . These forecasts are already seen as overestimates. Most baseline forecast envisions the deepest global recession since World War II. This study analyzes various economics impacts of the COVID-19 on a global scale. If the global recession expected due to the effects of the coronavirus (COVID-19) would lead to a decline in growth rate of global gross domestic product (GDP) between $2.0 \%$ and $10 \%$ in all countries in 2020, the number of unemployed people in the net food importer countries would increase between 14.4 million and 80.3 million; the biggest part of the increase would occur in low-income countries. As the pandemic has shown its most severe impact on the largest world economies, the study considers the developments in United States, Euro Area, Japan and China. The recessions in these parts of the world spreads to the other countries and one should primarily consider these regions. Next, we consider the trends in global trades, financial markets, and commodity markets. In association with the four regions of the global economy and trends in global trade, financial markets and commodity markets we consider recent developments in emerging markets.
\end{abstract}

\section{The following is a transcript of the keynote speech given by Prof. Dr. Mehmet Balcular.}

Dear colleagues, organizers and participants, I would like to welcome you to the 12th International Conference on Eurasian Economies. As the keynote speakers, I will be addressing today one of the hottest issues affecting the global economy the COVID-19 recession, or the pandemic recession. Currently, calling the situation, I believe, with a more proper name, would be the COVID-19 recession because there has been another pandemic recession during the Spanish fully at the end of the First World War. Firstly, I will try to draw your attention on the extent of the recession. We do observe frequent recessions in a capitalist economic system. Indeed, about every 4 to 7 years, it is expected to face a session in market economies. But, the COVID-19 recession is quite unique. Not because it is a pandemic recession it is because one of the deepest recessions we have experiencing since World War II.

I am going to be giving you a picture of this recession with its most attention taking features. Also, summarize the lessons we should be drawing from this recession for the future because it is a recession affecting the lives of the whole citizens of the world. My presentation will be concentrating on the economic aspects, but there are other aspects that cannot go unnoticed. The first question is what type of recession we are facing. It is one of the kinds that is called the sudden stop. Actually, this is not a typical sudden stop, it is more radical as it is caused by the COVID-19 pandemic. during the initiation of the pandemic in 1918-1920, the Spanish flue, many countries introduced lockdowns, the lockdown was initiated were first signals of the recession, that supply side effects were actually large during the shutdown. The supply side has been one of the initial reasons for the pandemic recession. Now, we understand that the recession is long here. And, it is a global recession. It is, at the moment, not questionable that we are going to have a global recession, but the question is, how deep it will be. Also, we are currently not sure how long the recession will last.

Recessions usually last for few quarters to, say two to six quarters on average. There has been a longer recession certainly in since in 1870 s which I going to mention later on. There is a lot of ambiguity about the current COVID19 recession, because it may be a long recession. The cumulative loss certainly is going to be quite big, if the recession turns out to be a prolonged one. Currently, United States economy on an annualized basis, has about $32 \%$ negative growth, that means a recession of $32 \%$ annual rate a in between April and June of 2020, that is the second quarter. The United States economy has been actually contracting by about $8 \%$ quarterly. The United Kingdom has been contracting about 20\%. Most of European economies were also contracting, about at $10 \%$ in Germany, a big recession. In the second quarter of 2020, supply, demand, trade and finance are severely disrupted globally. This is one big face of the recession. This is another dominantly supply side or supply shock recession, which is not mainly caused by demand. But demand side also contributed. It is much broader than we understand, it is both disruption of the demand and supply and this is also a one big side of this recession. The recession is hitting all countries globally. It is more sever in countries where the pandemic is actually more severe; those countries who are facing severe pandemic positive cases like the United States, like United Kingdom, Italy, Spain, Spain, and Brazil. The recessions in these countries are different than the others. There is a heavy disruption in global trade, tourism, commodity exports and external financing. And the countries that are heavily relying on these are hit by the recession deeper than the other countries, so, we can understand which countries are going to be the worst during this time, like Italy, Spain, Turkey and Greece are heavily hit because these countries do depend significantly on tourism and external financing. Indeed, there is a long-term implication of this recession.

Usually, in a market economy, when the recession is over the expansion picks up, and expect that the unemployment will decline and we will just put back the recession as history. The COVID-19 recession has 
significant implication for human capital development, because we have suspension of schooling and we have also a big detrition in the primary health care access. The damage to the healthcare system will take a long time to recover. Also, universities are not operating in a regular fashion. Schooling all over the world has been now largely interrupted, which will have long term human capital development implications and the reduction in the growth rates and the healthcare and economic consequences of the pandemic is going to be worse in the medium term for countries where there is widespread informality, what I mean by this is the informal economy where most of the activities are not actually formal or recorded. One of those countries is Turkey with an estimate about informal economy something about from 20 to $30 \%$. Why this is important, because the government cannot extend help or financing to informal sectors, because it is on records, as those people are put unemployed in the informal sector, they are not helped because they are not on the records. As they are not officially employed, they do not receive any benefits. So, in those countries like Turkey, where informal sector is big, actually, the effect is bigger than we understand. Indeed, at least 20 to $30 \%$ of those people who are initially became unemployed are the informal ones, because the government has been placing restrictions on firing. Therefore, most of the companies could not fire anybody because of the ban on firing, but those who are working informally became unemployment from the first day ahead. This trend will continue, not only in Turkey. Most of the emerging markets and the developing economies (EMDEs) has big informal sectors. One reason that the recession looks lighter in countries like Turkey is because these countries do have a large informal sector like. For instance, India, alike China, might have an economy with 20 to $30 \%$ of GDP generated by informal sectors.

The advanced economies are anticipated to contract about 7\% in 2020. Emerging markets and developing economies are expected to shrink by about $2.5 \%$. This is a big change because as a group, emerging market and developing economies did not contract in the last sixty years. That is, for six decades there was not negative or zero growth in emerging and developing countries as a group. First time in 60 years, these economies are going to be hit by a $2.5 \%$ contraction in the GDP adding this the informal sector shut downs makes the contraction even higher. That is, actually net contraction is something around $3.5 \%$ to $4 \%$ by the inclusion of informal sectors in these economies. Per capita income all over the world in 2020, given the lift of restrictions mobility and ending the lockdowns, is estimated to shrink about 3.6\% to 5\%. I am going to take the smaller figures to be optimistic. When the things turn out to be worse than what we expect, we can look into the worst-case scenarios. With a $3.6 \%$ contraction in the per capita income, millions of people will be put into extreme poverty conditions.

Because of the already high poverty rates in the low-income countries, millions of people will be experiencing extreme poverty. Millions of people will be living with an income of less than $\$ 1$ a day, which is the definition of extreme poverty by the United Nations. Let me consider, first, what has happened to per capita GDP and GDP worldwide. In my presentation, I am going to be going back to $1870 \mathrm{~s}$. So, we will be considering recessions in the last 150 years, seeing what has happened during this whole period in terms of depth and length of recessions. If you look at the right-hand side of Figure 1, which plots the index of per capita global GDP taking 1870 as 100 . And, the left-hand side is the index of global GDP taking 1870 as 100.

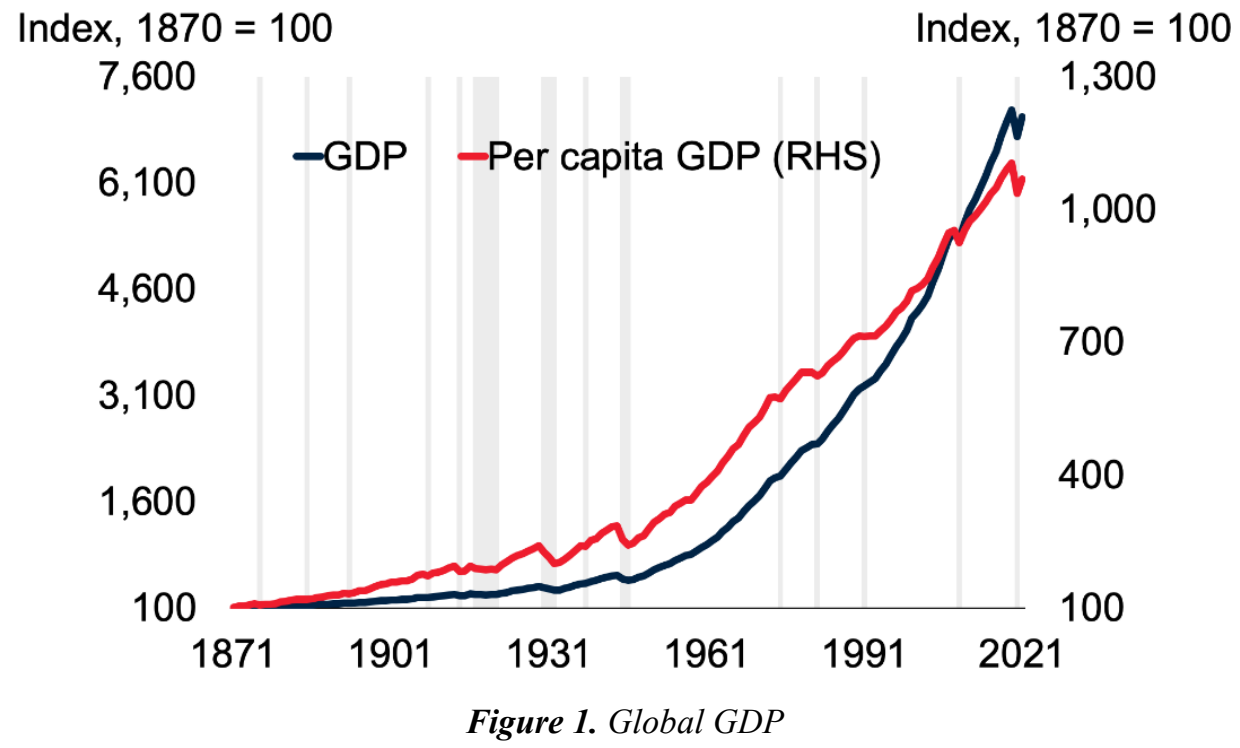

Since 1870, we have experienced a big welfare increase, and the global GDP increased from 100 to 7600 while the global per capita GDP increased from 100 to 1300. If we follow the per capita GDP line in here, or the GDP line, we will see that the COVID-19 recession created one of the largest crashes in both GDP and per capita GDP. It also looks like the recovery from this one might take long time. We have a similar recession, the Great Crash of 1930 and then the World War II, which may help to explain the case today. The recovery from the Great Crash actually, if you look at the trend line, took about 10 years or so. The World War II, on the other hand, to be restored 
back to the original trend path took about 10 years or so. We are, at the moment, not very sure when the full recovery from the COVID-19 recession will happen, because it is too early to make a judgement or make forecast on the numbers. But, the full recovery from the pandemic recession and restoring the pre pandemic trend growth may take anything from 3 to years to 10 years.

Let us look at GDP growth rates since 1870 in Figure 2. Looking 150 years back, we see that the first deepest recession is the one called the long recession, which was initiated in the United States but it was a global recession. The gray regions in this figure are the ones that were global recessions, by global I mean, it is not only the advanced economies, but also a large number of countries were affected from the recession. So, since 1870, if you count, we had 13 global recession and the COVID-19 is the 14th one. On average, our long experience about the global recession is that they come about every 10 years, but some of them are quite mild, something around zero to minus $1 \%$ GDP growth. A few of them are big, and these are the First World War, and then the first pandemic recession following that, which is the Spanish flu, then we have the Great Crash, then the Second World War, a global recession with the largest negative growth in the history. Next, we have the subprime crisis in 2007-2008. The last is the COVID-19 recession. We are hoping in 2021, the recovery from the recession will start, most estimates are so. My estimate is that, we are going to have about 3\% GDP growth in 2021 . Hopefully, this will be the reality. So, in any case, we are living the second largest global recession since the World War II, the one in subprime crisis was even milder than this one. Our estimate is about in this one is about something like $6 \%$, negative growth in 2020. Then recovery is started to pick up in 2021.

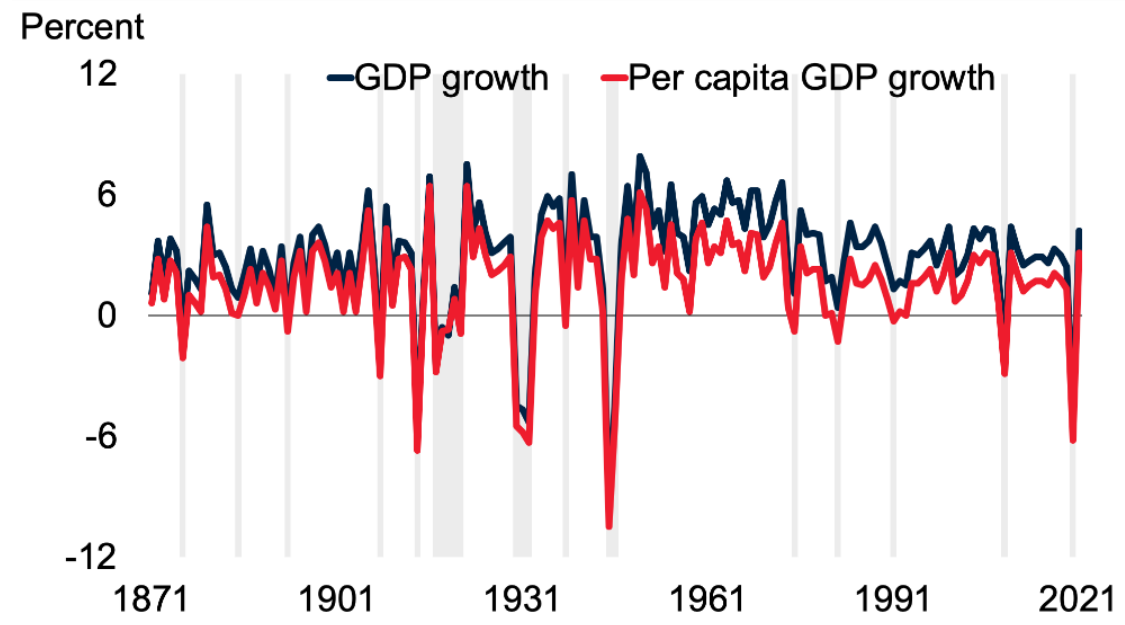

Figure 2. Global GDP Growth

Now, let me consider the growth rates in global recession periods and let us see what is expected with the COVID-19 recession compared those hundred in the last 150 years of global recessions. Considering the biggest ones with more than $3 \%$ cumulative GDP contraction, if you see the first one, we had about minus $6.7 \%$, negative growth. Then, right after the First World War, this is the actually Spanish Flu period, the Spanish fully flu starts in 1918 and goes up 1920. There were already some recessionary signals before the Spanish Flu, but the Spanish Flu is mixed with the 1917 recession and ended up with 4.4\% decline. So, we can call this one, the first pandemic recession and the second one is the 2020 COVID-19 recession. Adding up the cumulative declines over the recession period, the Great Crash ended up with cumulative 17.6\% decline the global GDP. The Second World War follows with minus $15.4 \%$ cumulative change in GDP. If you look at the Great Recession, following the subprime financial crisis, it is depth was about half of what we are experiencing now. The minus $6.2 \%$ GDP decline is the most optimistic estimate for 2020. It may be something around this minus $6.2 \%$. It may go up to minus $9 \%$. We are not yet through the pandemic yet. We will go to the third and the fourth quarter of 2020 with a recessionary state. So, if you compare this one, which now even the young economists in our session already know, with the history of the Great Recession of 2007-2009 with 2.9\% decline. This figure is about half of what we are experiencing now. In the Great Recession period with $2.9 \%$ negative growth, the emerging and developing economies had a positive growth. This time, it is more extensive than the Great Recession, as the emerging and developing economies as group will have a negative GDP growth. 


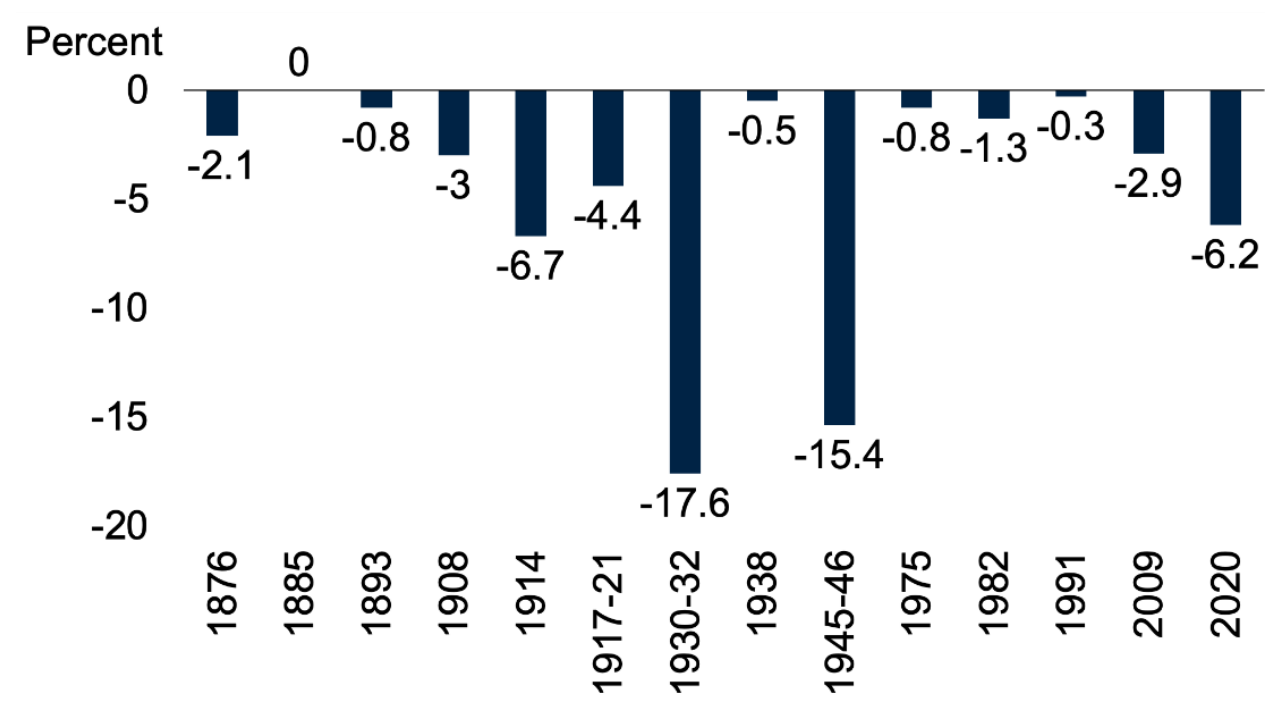

Figure 3. Cumulative Global GDP Decline during Global Recessions

As the figures show, we are living in a very deep recession period now. We have to see that the extent of this recession is much beyond what we initially anticipated.

Another important aspect recession that I am going to look at is how global is the recession. Let us count the number of countries in the world, I mean, affected by the global recessions and recessions of the history, and calculate the percentage of countries that are affected by the recession. This percentage is given in Figure 4. So, this is a measure of how global the recession is. Let us start from the first pandemic recession that was a global, as it was a pandemic and quite global, and the First World War. These ones affected about $70 \%$ of the whole economies, the Great Crash effect about $80 \%$ of the world economies. The Great recession of 2007-2009, only had an about $60 \%$ of the world economies affected. Now, the COVID-19 recession is affecting $90 \%$ of the world economies. So, extent of the COVID-19 recession is the biggest in the last century and a half. In the last 150 years, we did not have such an extensive recession in the world. This means much larger proportion of the world population will be affected from this recession. Almost no country is free of the COVID-19 recession. It looks like all countries are going to feel the influence of the recession, covering almost the whole world population.

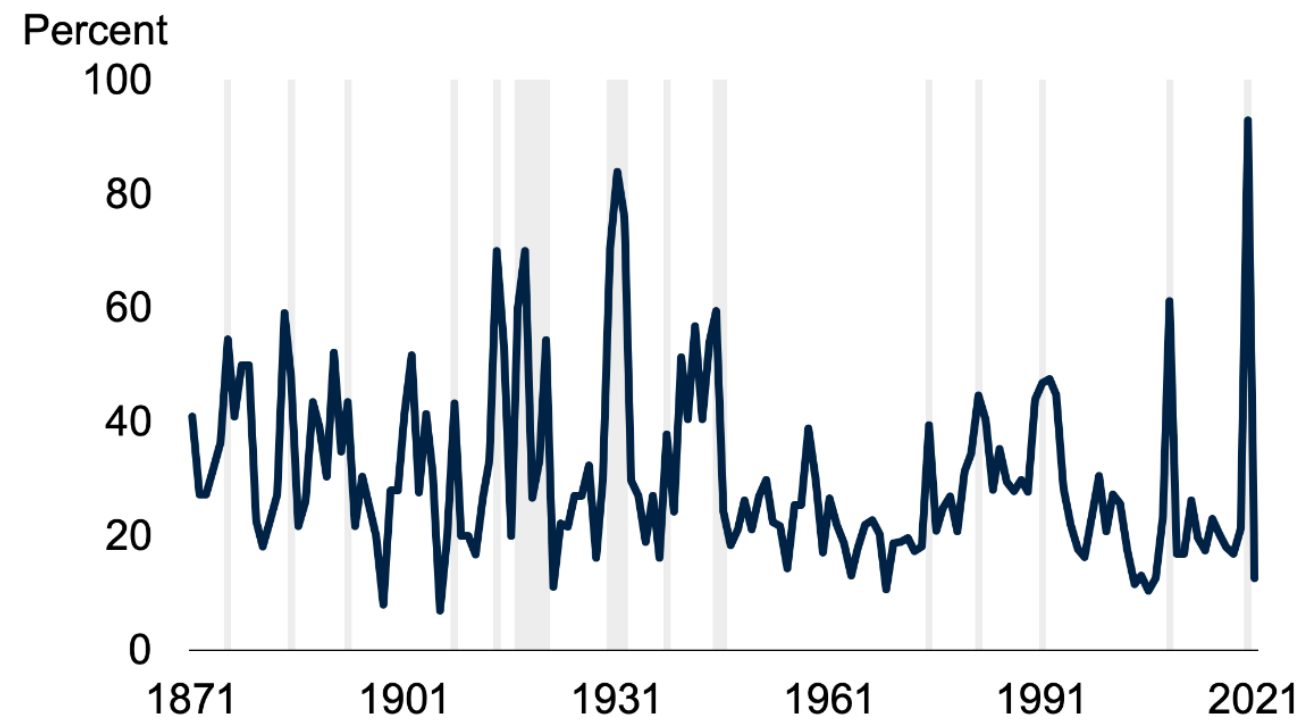

Figure 4. Number of Economies in Recession (\%)

Our universe 7.8 billion people and $90 \%$ of the economies such a large number of people living in are affected from the recession. It is not difficult to imagine how many of people and families will be suffering from this recession. It is the most extensive recession of the last 150 year in terms of the coverage of the world economies.

Let me also illustrate the deepness of the COVID-19 recession in comparison to recent history. How deep is the COVID-19 recession in comparison to other recessions since 1970 is illustrated in Figure 5. The figure uses an index of GDP taking a value of 100 in period t-1 for a recession that started in period t. In the figure two earlier recessions we consider are the recession of 1975, which was caused by oil shock and the 1982 recession, which was partly due to oil price hike, but it was also initiated by the Iranian Revolution. However, the 1982 recession 
was indeed a monetary recession. Most of the central banks in the world were afraid of inflationary pressures, and they were actually pressing the pedal on the money supply. This caused a deep recession in most of the advanced economies and many of the emerging markets are affected. Next, I will put the 1991 recession on the figure. I will compare the GDP index of last two deep recessions as lines in the figure. The gray area represents the region covered by the minimum and maximum of the 1975, 1982 and 1991. And the blue line represents the GDP index during the Great Recession following the subprime crisis period. This recession was actually globally felt in 2009 . That is why I call this one as 2009 recession. And, the red line represents GDP index of the COVID-19 recession. So, the $\mathrm{t}$ is the recession year, that means it is 2020 for the COVID-19 recession and 2009 for the Great Recession.

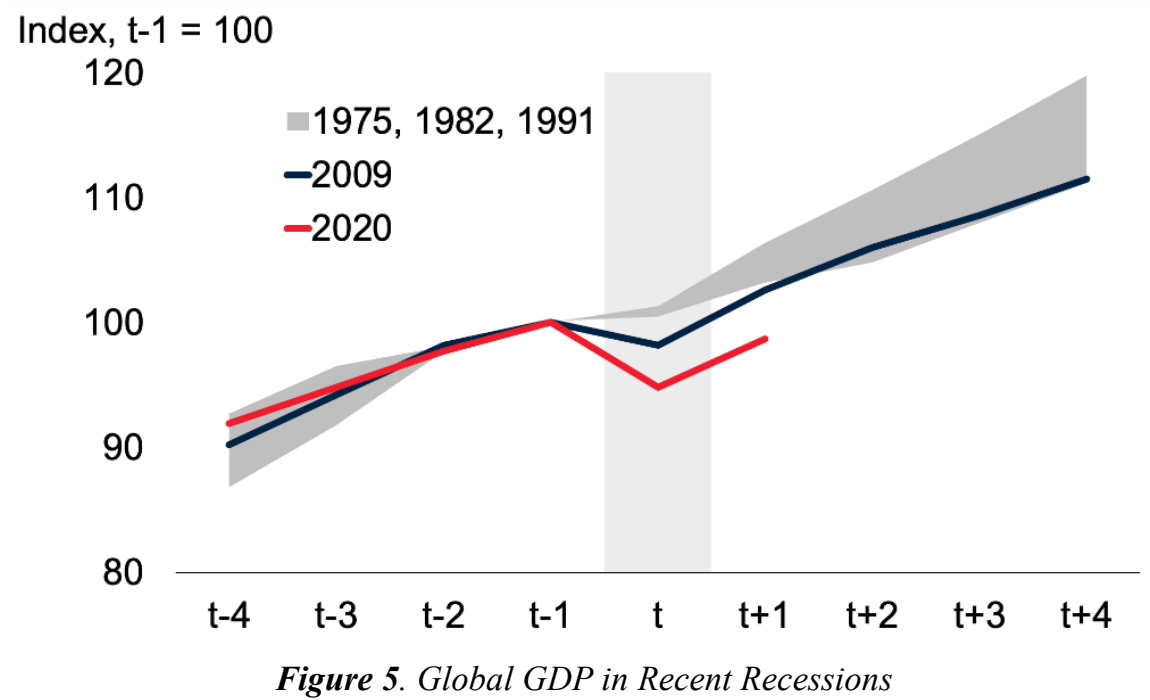

We will consider a period covering four years before and four years before around the recession year $t$. For instance, for the 2020 COVID-19 recession, a period from 2016-four years before the recession start year-to 2024-four years after the recession start year will give us a sense of how deep the recession that we are living at the moment, and also how long the recovery will take. So now let's look at the numbers. Since I cannot compare the numerical values, I am going to use the GDP index that takes a value of 100 in year $\mathrm{t}-1$. So, all the recession GDP indexes are equal at time $\mathrm{t}-1$. So, if the index is 90 in a period, that is a $10 \%$ decline in the GDP compared to the year before the recession. At the moment, for the COVID-19 recession, the index in around 94, meaning a $6 \%$ negative growth in the COVID-19 recession. Let us look at the path of the line and see how it compares with the great recession of 2009. This will help us to judge how long it will take to recover from recession as deep as you this one. Currently, given the path of the line the recovery to the level before the recession is going to take something around 10 years or so. So, it will be $t$ a deep and long recession. We should understand that we are living the deepest recession since 1970. If you consider the global economy, we are hit by the most extensive and the deepest recession of the last 50 years.

Per capita GDP figures are more important than the GDP as it will adjust the GDP for the population. It is also extensively used as a measure of personal welfare then the GDP. The per capita figures are also more relevant to part of the world population that will be affected by the recession. The global per capita GDP path in comparison to recessions after 1970 is given in Figure 6. Again, the figure show the recession is the deepest of the recessions of the last 50 years. We also note that the recovery will probably be faster for the per capita GDP than the GDP level itself because we are expecting the emerging and developing countries, which are more dynamic in terms of their economies and young population, will probably recover faster. And those advanced economies, which were already experiencing slow growth in the last decade, are likely to recover later than the emerging markets and developing economies. 


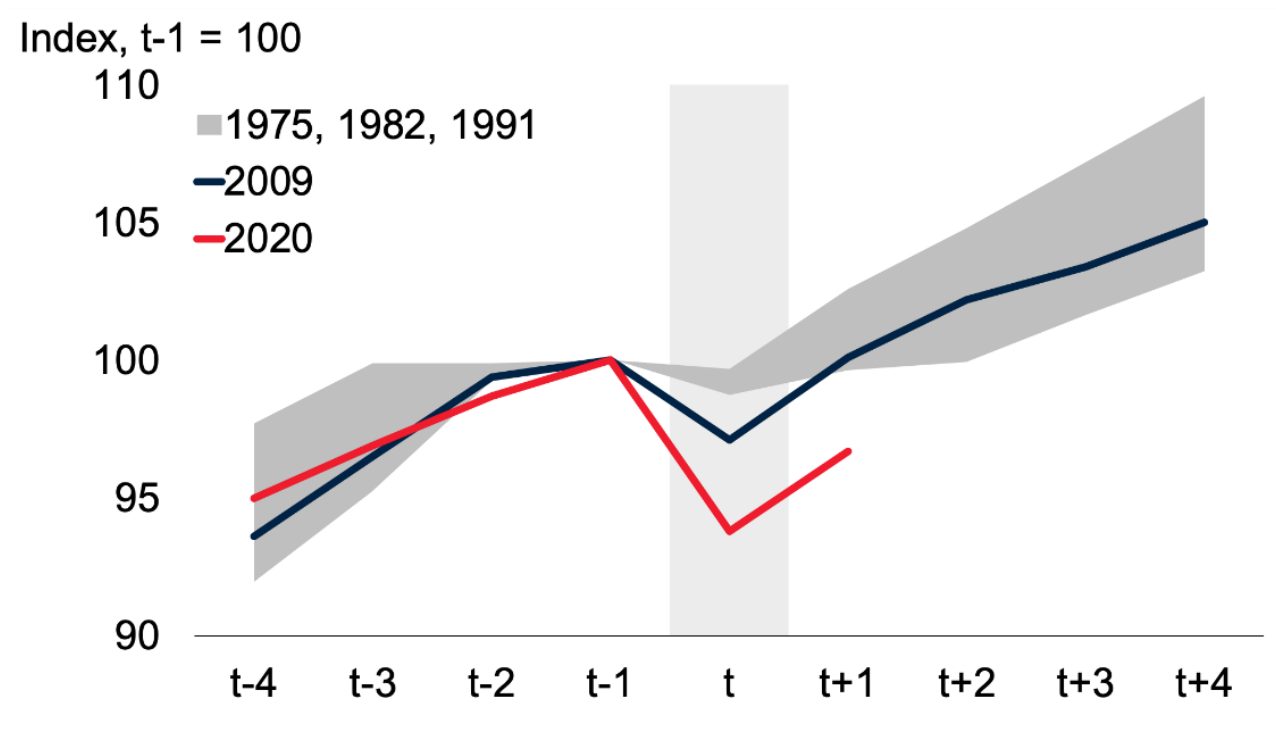

Figure 6. Per capita Global GDP in Recent Recessions

This point is well illustrated by the consensus forecast of GDP growth for the period February 2020-June 2020 given in Figure 7.

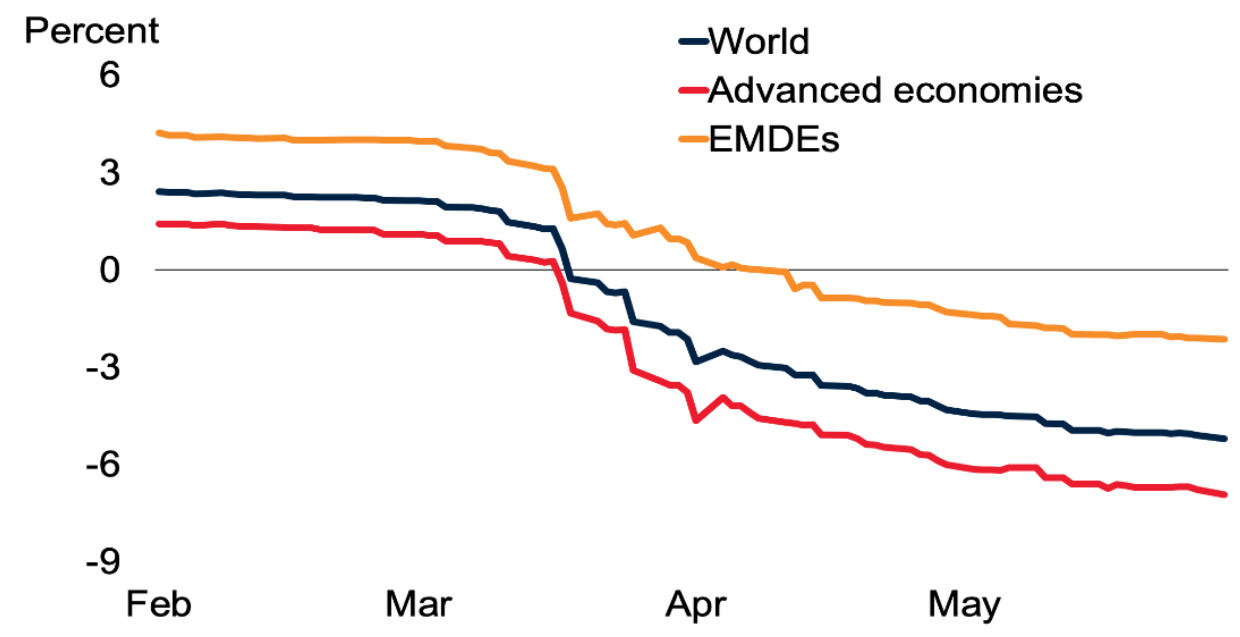

Figure 7. Consensus Forecasts of GDP Growth for February-June 2020

Let us know look at the e initiation of this recession. Let us go back and consider the GDP growth rates in Figures 2 and 5. As we see from this figure, the GDP growth rates suddenly makes a sharp decline in the second quarter of 2020. So, the recession initially came as a supply shock. The recession started initially as a sudden stop of the production because of lockdowns and restrictions on trade and shipments of goods across the countries. This sudden stop-initiated supply shock arose mainly because of lockdowns, as there was interruption in the supply chain and the world trade. There was also interruption in financial flows. Most countries who are dependent on external financing experienced actually a difficulty to finance their debt and imports.

Now let us look at the retail sales, which gives us an idea about the demand. Figure 8 presents the retail sales index during the major global recessions since 1970. The demand did not initially contract much because consumers were not sure on how long and how extensive the COVID-19 pandemic would be. However, the retail sales made a sharp decline in the second quarter of 2020, a large negative demand shock. So, the weak demand is likely to continue because the pandemic progressed fast and affected most of the world. A lot of uncertainties remain about the evolution of the COVID-19, so, the demand may stay quite weak even until the second quarter of 2021. Thus, the COVID-19 recession has unique feature, as initial negative supply shock further reinforced by the demand shock that followed it. 


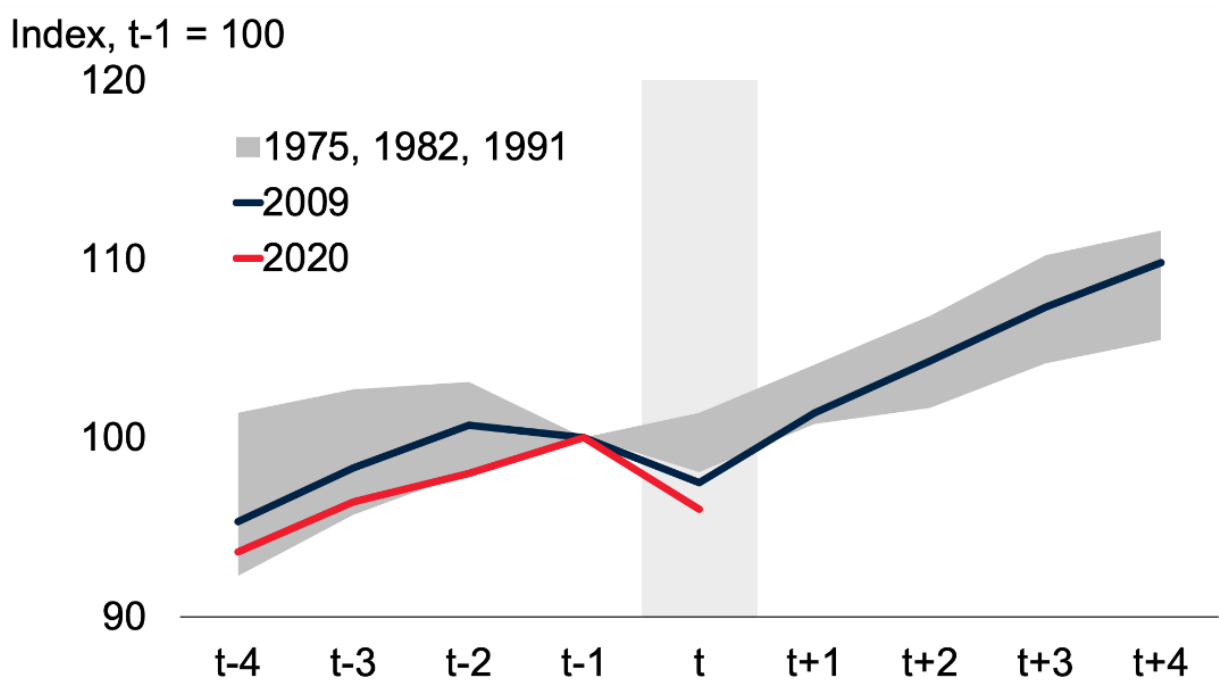

Figure 8. Global Retail Sales Index in Recessions

A question yet remains to answer: Why is the COVID-19 pandemic recession so different than the others? First and foremost, the recession was initiated by a supply shock, because of the lockdowns, interruptions in the supply chain and the trade flows. Second, high unemployment leaded to significant declines in personal income which triggered a demand shock. But, is all we can say? can economists say anything else other than supply and demand shock? Do we know what are the root causes of the weak demand and supply shocks? We tend to link everything to supply and demand. Do we have a better story to explain the causes of the weak demand? I will quote an important statement from Keynes: "Many candid persons, when confronted with the results of Probability, feel a strong sense of the uncertainty of the logical basis upon which it seems to rest." (Keynes J. M. 1921, A Treatise on Probability. London: MacMillan).

This is something about the core causes of many events in economics. So, he links behavior of economic actors to the relevant key "probabilities", which inherently contain uncertainty. I am one of the researchers who have been giving a lot place to uncertainty in many of my papers, I probably have more than 50 work somehow related to uncertainty, all published in the last 10 years. I believe most of the core causes in economics is linked to uncertainty. There are three core decision makers and three core decisions in economics: (1) Firms make decisions to maximize profits, thus, firms make decisions on whole future path of profits not only today. So, the whole future flows of revenue and cost are relevant, when firms are making a decision on maximizing profits. (2) Consumers make decisions on maximizing utility. But, they consider the whole future lifetime utility, not only today's utility. For instance, when a consumer considers a decision on buying a house or placing some money into his saving account, she does not consider only the next year, but she considers her whole lifetime, maybe even beyond lifetime. So, the whole future flows of income and consumption are relevant in consumer decisions. We should approach the many decisions we study in economics from this perspective lifetime perspective. We should look into how firms and consumers make decisions in real world, not how textbook consumers and firms make decision. Consumers and firms make decisions by considering the whole future relevant to them. But, future is unknown and characterized by uncertainty. Uncertainty radically affects all decisions. In the face of the COVID-19 recession, in order answer the questions such as why investment is cut so badly, why consumers are so reluctant to spend, and why consumers do panic buying, we need to consider the most relevant characteristics of future, which is uncertainty. The future of the COVID-19 pandemic is so uncertain that firms and consumers are pushed into a state of waiting, cutting all spending. Thus, the root cause of the recession being so deep is the uncertainty that has been introduced by the COVID-19 pandemic. In order to bring some evidence on my case I present the world index of uncertainty in Figure 9. 


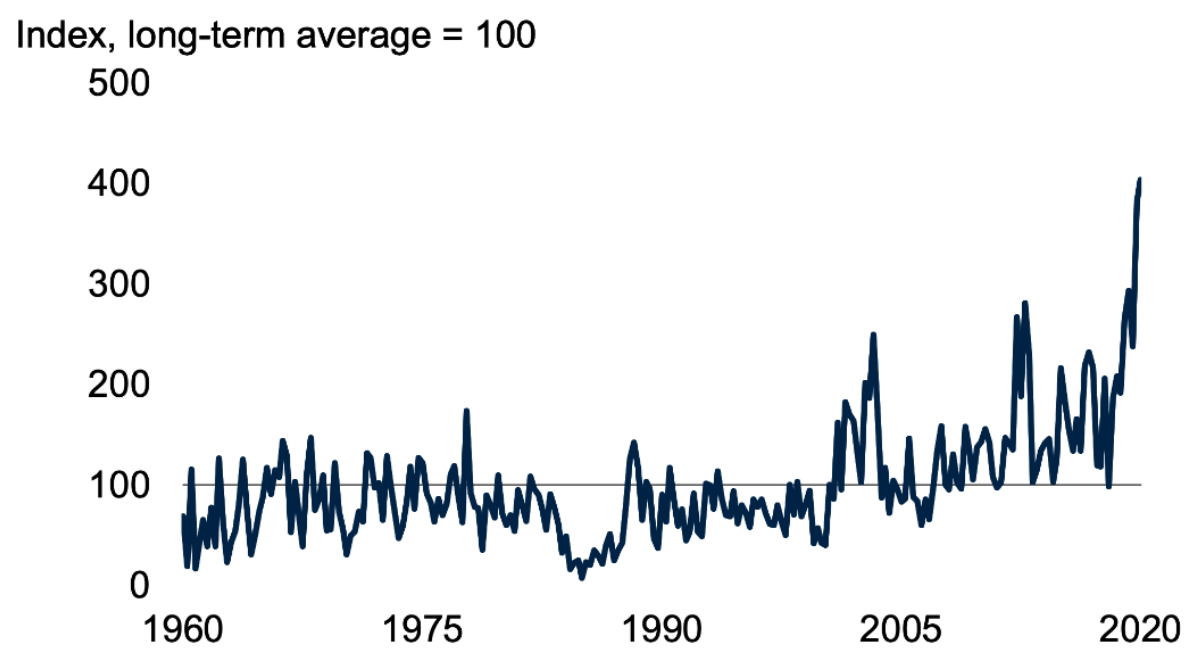

Figure 9. Global Index of Uncertainty

The index is normalized such that the long-run average id 100. The average uncertainty 100 is exceeded significantly during 2003, 2012, and 2020, with peak values 250,280 , and 403 , respectively. Thus, the global uncertainty index is now during this pandemic is four times larger than the long-run average, and it is about 1.5 times larger than the 2012 peak, which is the second largest peak. This figure shows so radically that we are in an era of the greatest uncertainty of the last 70 years. It is this uncertainty that characterizes the COVID-19 uncertainty. 